\title{
Development of Test Equipment for the Performance Evaluation of a Dust Monitor Used in Soot and Smoke Generating Facilities
}

\author{
Masashi WADA $^{1 *}$, Masashi TsujI ${ }^{2}$, Fujio KAYAHARA ${ }^{2}$, and William AVERDIECK ${ }^{3}$ \\ ${ }^{1}$ Research Institute of Environment Agriculture and Fisheries Osaka Prefecture, 442 Shakudo, Habikino, Osaka, 583-0862, Japan \\ 2 KANSAI Automation Co., Ltd., 2-14 Togano, Kita-ku, Osaka, 530-0056, Japan \\ ${ }^{3}$ The Source Testing Association, Knowl Piece, Wilbury Way, Hitchin, SG4 0TY, UK
}

\begin{abstract}
A dust monitor is a device that measures dust concentration continuously in a flue gas. In Europe, a certification system has been established by TÜV and MCERT, and if formal certification is obtained by those system, it will be legally recognized as a continuous monitoring system of dust concentration from the facilities. In Japan, emission regulations have been introduced under the Air Pollution Control Act to monitor the emission of dust from facilities. Although the Act does not currently permit the use of dust monitors for dust concentration measurements, the related JIS standards have promoted above method's introduction. In this work, flue test equipment aiming at the construction of a performance evaluation system of various dust monitors was developed to secure accurate dust concentration measurements for dust monitor management. As a result, increase in the diameter of the flue, optimization of rectification and dust generation, and improvement of the evaluation component made it possible to respond to the evaluation of dust monitors. The device was equipped to generate gas containing dust with any concentration in a constant velocity flow. It could evaluate the correlation between the analysis values of JIS Z 8808: 2013 and those of various dust monitors.
\end{abstract}

\section{Introduction}

A dust monitor is a device that continuously measures the dust concentration in a flue, chimney, or duct. They have been widely used in thermal power plants and waste treatment incubators due to their ability to constantly evaluate the operation status of exhaust gas treatment facilities.

In Japan, however, despite having a standard measurement method for dust monitors, there is no standard regarding reliability of the measurement results, making it was impossible to uniformly evaluate the performance of various dust monitors. The Air Pollution Control Act currently requires the measurement of dust concentration in exhaust gas as often as once every few months. If the use of continuous measurements, which have been enabled by the dust monitor, is recognized by the Air Pollution Control Act, it will be possible to analyze exhaust gas concentrations accurately and manage treatment facilities appropriately.

In Europe, however, the dust monitor is legally recognized as a continuous monitoring system for dust concentrations from stationary sources (CEMS, Continuous Emission Monitoring Systems), and has already been already used in emission control (Castellani et al., 2014). However, CEMS require certifications, such as those from TÜV: Technischer Überwachungs - Verein (Germany) or MCERT: Monitoring Certification Scheme (UK) based on the EN standard (EN14181: Stationary source emissions Quality assurance of automated measuring systems, or EN15267: Air quality Certification of automated measuring systems). In EN15267, requirements for automatic calibration are stipulated in order to maintain automatic analyzer reliability, to ensure that equipment cannot be set or data cannot be searched by unauthorized persons, and that the presentation of the confirmation method of zero span drift is correct.

In Southeast Asian countries that do not have a certification system, specifications in line with European and US standards are required, and therefore, the need for TÜV and United States Environmental Protection Agency (USEPA) certification is increasing. In addition, there may also be problems with infrastructure exports as there is no international certification (e.g., USEPA or TÜV) specified in the purchase specifications of the partner country. For Japanese companies, response to requirements such as EN15267, and EN14181, in the expansion of overseas markets in Europe and Asian countries are issues that need consideration.

Therefore, the use of dust monitor data as evidence for compliance with management status as a standard performance evaluation method is required in Japan. In addition, to make it possible to add the dust monitor method to official laws in the future, JISC (Japanese Industrial Standards Committee) is promoting the development of these standards (Niwa et al., 2010; Tamori, 2014). 


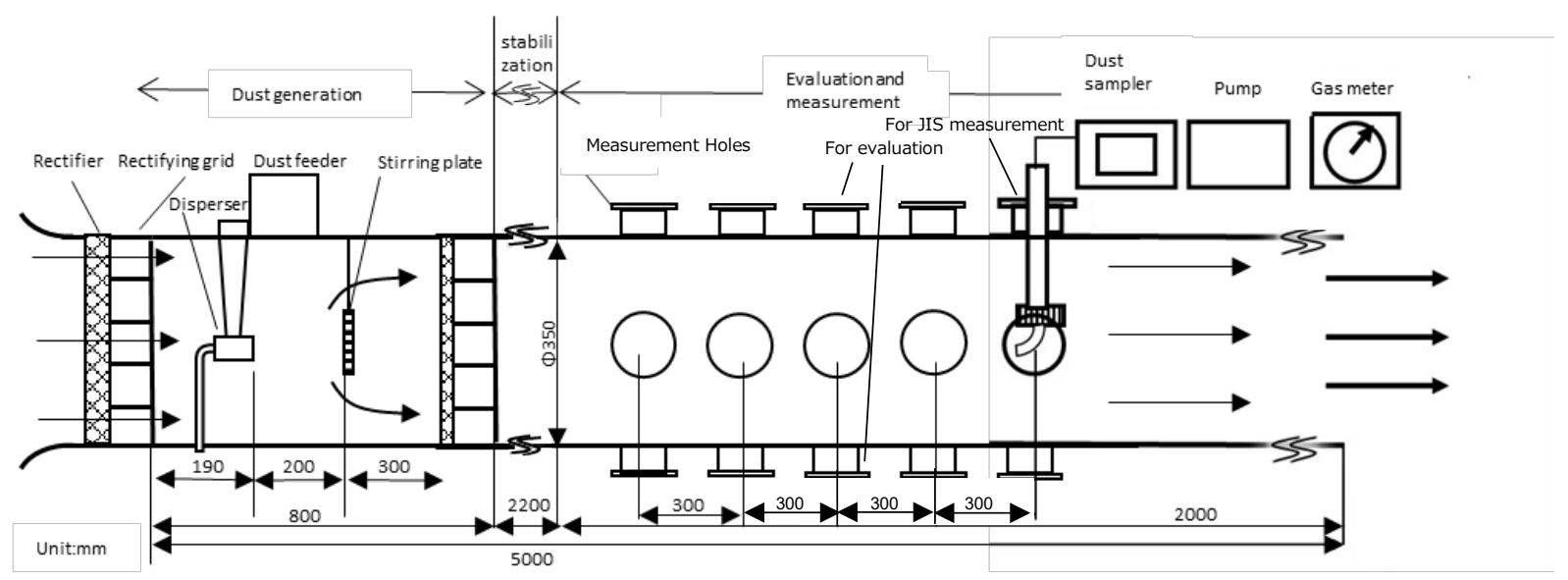

Figure 1. Test equipment for dust monitor performance evaluation.

In this work, development of flue test equipment was carried out for the purpose of establishing a unified evaluation method for various dust monitors and constructing a public performance evaluation facility that was not possible before. This is a technical report of our work, and presents current device performance, results of attempting to evaluate dust monitor performance, and issues to be addressed.

\section{Test apparatus and Method}

\subsection{Outline of flue test equipment}

A schematic of the flue test equipment is shown in Figure 1. In this test apparatus, test dust is quantitatively supplied from a dust feeder (Arufa Co. Ltd., Millifeeder MF15A$\mathrm{C} 1.5 \mathrm{~L}$ ) into the duct (inner diameter $\varphi 350 \mathrm{~mm}$, overall length approximately $5 \mathrm{~m}$ ) and dispersed in an air flow of constant flow velocity. The dust feeder is a coil rotary type and can be set to an arbitrary dust concentration by changing the number of revolutions and adjusting the amount of dust supplied. By installing a stirring plate, a straightening plate, and a straightening grid, optimum air flow stirring and straightening can be performed. The measuring device is installed and measures in a measurement hole $3.5 \mathrm{~m}$ downstream of the dust generator.

Measurement holes for analysis specified in the JIS Z 8808: 2013 are provided at $600 \mathrm{~mm}$ downstream of the holes for target dust monitoring. In particular, in the case of the light transmission type, it is necessary to secure

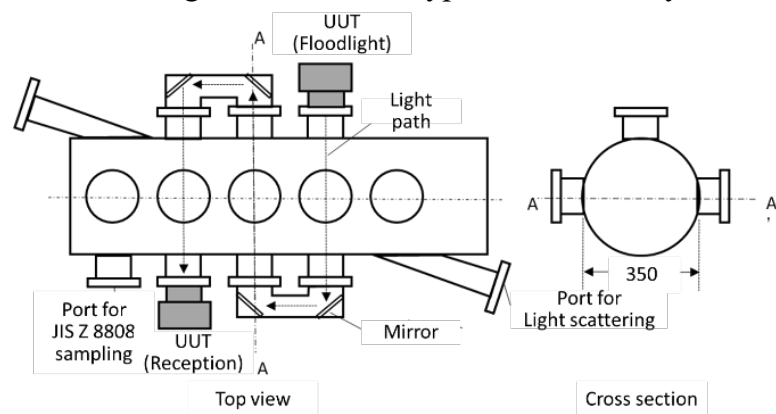

Figure 2. Evaluation measurement unit (when light transmission type is installed) a sufficient light path length, and, in addition, to have measurement holes at 3 places (total 5 holes), a and to have the beam pass through the flue several times by using reflectors (Figure 2). A plurality of measurement holes is provided in the vertical and horizontal directions, and the distribution of the flow speed and the dust concentration can be measured in 5 cross sections. Among them, a special pitot tube and thermocouple thermometer were installed at one place in the upper section to constantly monitor the flow velocity and temperature.

\subsection{Performance measurement of the test dust generator}

\subsubsection{Airflow stability performance}

In order to confirm the airflow stability performance, the flow velocity distribution was measured in a plurality of cross sections in the measurement unit. The measurement section was divided into 10 equal parts in the vertical and horizontal directions, and the measurement was performed 10 times at each point, $(n=10)$. For measurement, a hot-wire anemometer (KANOMAX Co. Ltd., Model 6501, measurement range 0.05 to $50 \mathrm{~m} / \mathrm{s}$, measurement accuracy $2 \%$ ) was used. The measurement was performed at the maximum output of the blower.

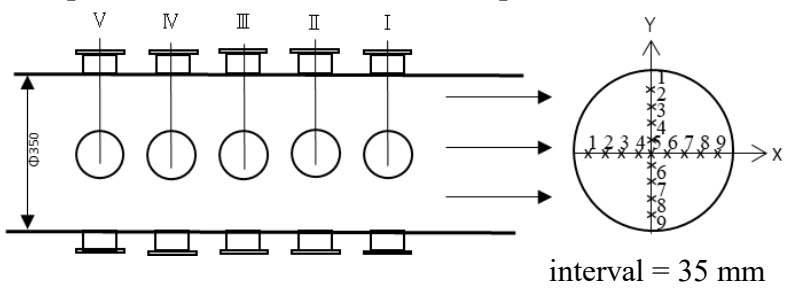

Figure 3. Sampling point of flow velocity

\subsubsection{Dust concentration stability performance}

\section{(1) Stability of the dust supply system}

In order to confirm the dust concentration stability performance, the stability of the dust supply device was confirmed. The dust feeder is a coil type and has a mechanism that can stably supply the amount of powder 
by changing the number of rotations and is controlled by knob adjustment. The control of the feeder was pinched and adjusted so that the electrical output to the motor was at a predetermined voltage $(1,3,5$, and $7 \mathrm{~V})$. Then, the linearity was confirmed by measuring the dust supply with an electronic balance (Sartorius, CP 64, $64 \mathrm{~g}, 0.1 \mathrm{~g}$ ). JIS Z 8901: 2006 powder fly ash (JIS 10 type) (median diameter: 4.8 to $5.7 \mu \mathrm{m}$, particle density: 2.0 to $2.3 \mathrm{~g} / \mathrm{cm}^{3}$ ) was used as the test dust. The standard dust used in the test was spread flat in a flat box, dried in a thermostat at $110^{\circ} \mathrm{C}$ for $1 \mathrm{~h}$, allowed to cool in a desiccator overnight, and transferred from the desiccator to a closed vessel immediately before use.

\section{(2) Disperser and diffuser performance}

In order to confirm the performance of the disperser and the diffuser, dust dispersion was observed. By adjusting the flow rate of the clean air and the position of the nozzle that ejects the air, it is possible to change the opening ratio of the powder supply pipe connected to the upper part and the connection part, and thus, the dispersion force can be adjusted. A predetermined amount $(0.15 \mathrm{~g})$ of test powder was supplied, and the state of dispersion was evaluated by photography with a high-speed camera.

\section{(3) Dust concentration stabilization performance}

In order to confirm the stability of the dust concentration in the measurement section, the dust concentration of dust air generated in the duct was measured by the method of JIS Z 8808: 2013, and the linearity with the set value (output voltage) of the feeder was analyzed. The feeder was controlled as the electrical output to the motor was at a predetermined voltage (1, 2, 3, 4 and $5 \mathrm{~V})$.

\section{(4) Particle size distribution of generated dust}

A particle size distribution measurement was performed to confirm the size of the dust generated in the duct under the test conditions. Measurement of the particle size distribution was performed according to the JIS K 0302: 1989 method of dust particle size distribution in exhaust gas. An Andersen stack sampler (Tokyo Dylec Co. Ltd., AS-500) was used for the measurement.

\section{3 Correlation test with the JIS Z 8808: 2013 analysis value of dust monitors}

Using the flue test equipment, the value of the dust monitor and analysis of the value defined in JIS Z 8808: 2013 was measured. Evaluation was attempted with two types of dust monitors: an electro-dynamic type and a light transmission type. Among the measurement holes located on the downstream side, when sampling in the analysis specified in JIS Z 8808: 2013 with the measurement holes on the side, install a special-type pitottube and thermocouple thermometer in the measurement hole on the top, and the flow rate and temperature were constantly monitored. At the time of sampling, measurement was carried out by fixing to a measurement point that causes as little turbulence as possible.

In each dust monitor, the $0-100 \%$ output was adjusted to be approximately $0-100 \mathrm{mg} / \mathrm{m}^{3}$, and the generated dust concentration was also adjusted to be less than $100 \mathrm{mg} / \mathrm{m}^{3}$. The measured output $(0-100 \%$ output at 4-20 mA) was recorded. The sampling period of the recorder was $1 \mathrm{~s}$ and the average value of the trend indicated during the analysis execution time specified in JIS Z 8808: 2013 was taken as the indication value (\%) of the dust monitor. In addition, the power supply conditions for the dust monitor were an $\mathrm{AC}$ voltage of $100 \mathrm{~V}$ and a frequency of $60 \mathrm{~Hz}$.

As a test dust, powder fly ash (JIS 10 type) was subjected to the same treatment as in the preceding paragraph. The dust concentration was measured in accordance with the official method of JIS Z 8808: 2013 and a common-type automatic sampling device was used (Okano Seisakusho Co. Ltd., Dustac sampler ESA-703). The sampling filter used quartz fiber cylindrical filter paper (ADVANTEC, 88R) for dust collection. Before use, filters underwent heat treatment at $110{ }^{\circ} \mathrm{C}$, left in a constant temperature and humidity chamber at $20{ }^{\circ} \mathrm{C}$ and relative humidity of $50 \%$ for 24 hours or more, and weighed with an electronic balance (Metler Toledo, XS205 ) with a sensitivity of $0.01 \mathrm{mg}$. In addition, after sampling, the filter was left in the same chamber for $24 \mathrm{~h}$ or more and then weighed.

\section{Results}

\subsection{Performance measurement of the test dust generator}

\subsubsection{Airflow stability performance}

In order to confirm the airflow stability performance, the flow velocity distribution was measured in a plurality of cross sections of the measurement unit. Figures 4 and 5 show the flow velocity distribution at each part. The upper limit of the flow velocity was $10 \mathrm{~m} / \mathrm{s}$. Airflow stability within $\pm 1 \%$ was confirmed except for the boundary.

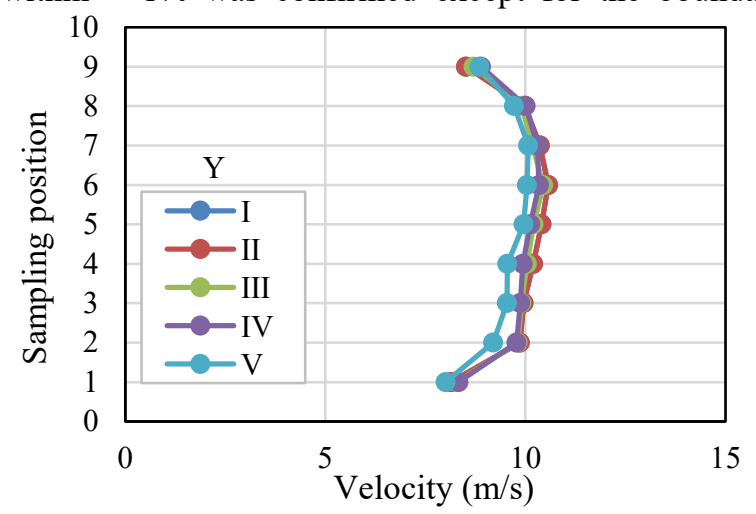

Figure 4. Velocity distribution in each vertical cross section. 


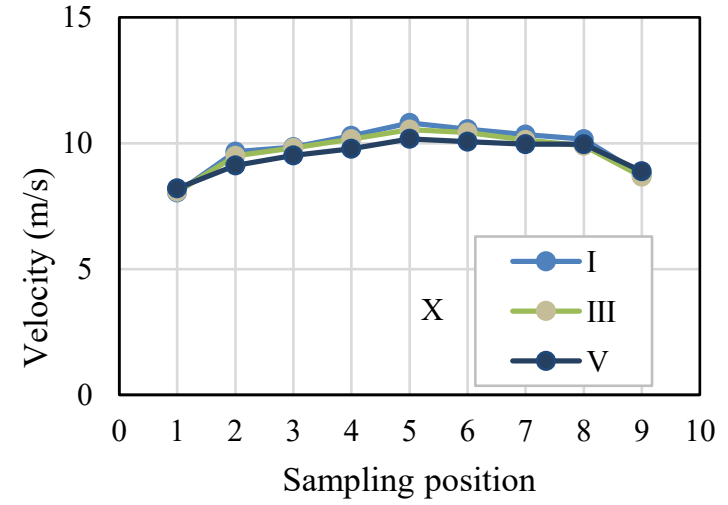

Figure 5. Velocity distribution in each horizontal cross section.

\subsubsection{Dust concentration stability performance}

\section{(1) Supply stability of the dust supply system}

In order to confirm the dust concentration stabilization performance, the supply stability of the dust supply device was confirmed. The relationship between the electrical output of the feeder and the amount of dust supplied is shown in Figure 6. The electrical output and the dust supply rate showed a high correlation $\left(\mathrm{R}^{2}>0.99\right)$.

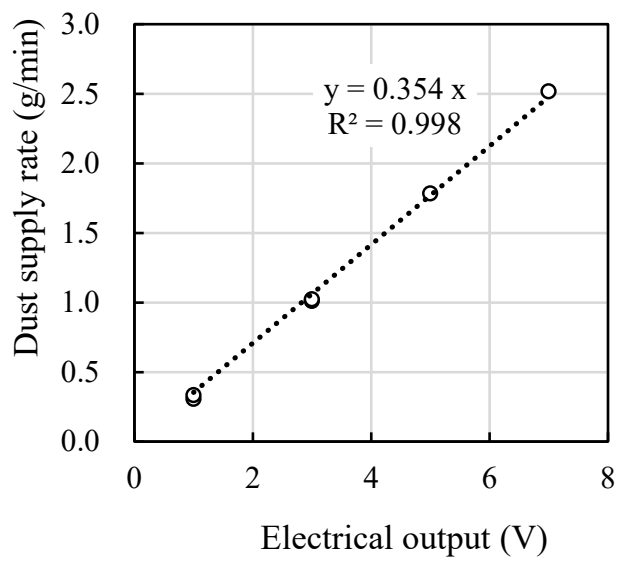

Figure 6. The relationship between the electrical output of the feeder and the amount of dust supplied.

\section{(2) Disperser and diffuser performance}

The performance of the disperser and the diffuser was confirmed. A predetermined amount $(0.15 \mathrm{~g})$ of test dust was supplied, and the state of dispersion was evaluated by photography with a high-speed camera (Table 1). When the airflow for the disperser was constant, the spread of dust and the dispersion were larger, as the opening ratio of the powder supply pipe was smaller. However, when the dispersion was small, due to the opening ratio being larger, many aggregates were observed, but they collided and were removed by the diffusion plate. After the diffusion plate, the dust distribution was uniform (Figure 7).
Table 1. Dust discharged from the disperser
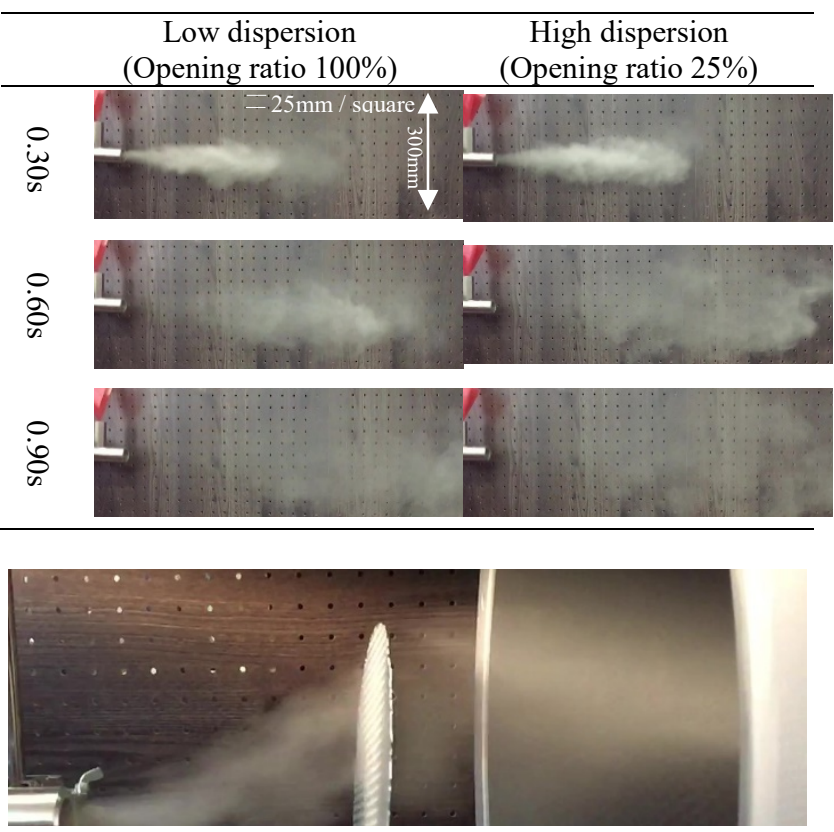

Figure 7. Effect of the diffusion plate

\section{(3) Dust concentration stabilization performance}

The stability of dust concentration was confirmed in the measurement section. Air containing dust generated by the dust feeder was analyzed in accordance with JIS Z 8808: 2013 at the measurement hole, and the linearity was confirmed by comparison with the set value (output voltage) of the feeder. Figure 8 shows the relationship between the electrical output of feeder and the dust concentration. The output voltage and the analysis value show a high correlation $\left(\mathrm{R}^{2}>0.97\right)$.

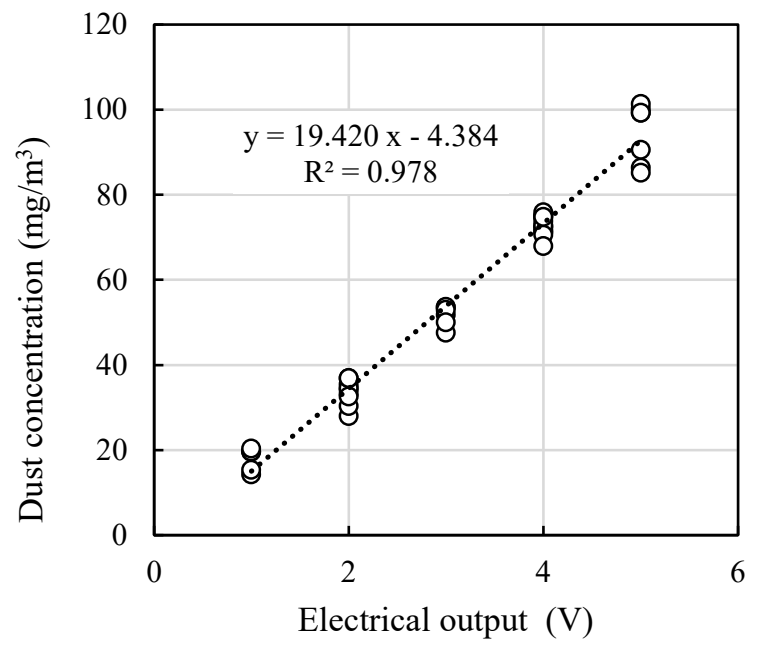

Figure 8. Relationship between the electrical output of the feeder and the amount of dust supplied

\section{(4) Particle size distribution of generated dust}

Particle size distribution measurement was performed to confirm the particle size in the dust-containing gas. Figure 9 shows the result of the particle size distribution measurement. The median diameter $\left(\mathrm{dp}_{50}\right)$ of the 
generated dust was approximately $5 \mu \mathrm{m}$, and it was confirmed that dust equivalent to the sample (JIS 10 type fly ash, median diameter: 4.8 to $5.7 \mu \mathrm{m}$ ) was flowing. It was confirmed that particles were generated well in the duct.

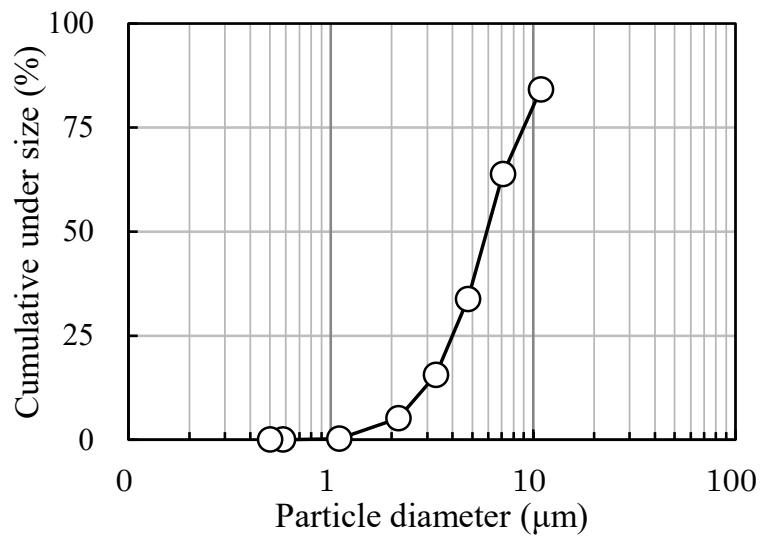

Figure 9. Particle size distribution of the dust-containing gas in the duct generated by JIS 10 type powder fly ash

\section{2 Correlation test with JIS Z 8808: 2013 analysis value of dust monitors}

By measuring the indicated value of the dust monitor using the flue test equipment and the analysis value defined in JIS Z 8808: 2013, data statistical processing was performed according to JIS Z 8852: 2013, a calibration curve was obtained, and a correlation coefficient $\left(\mathrm{R}^{2}\right)$ was calculated. Evaluation was attempted using two types of dust monitors: electro-dynamic type and light transmission type. Figures 10 and 11 show the results of the correlation tests with the JIS Z 8808: 2013 analysis value of each dust monitors. The correlation coefficient $\left(\mathrm{R}^{2}\right)$ of each device was 0.96 or higher. Although the measurement was made in a narrow duct diameter, it was possible to measure the light transmission type with sufficient accuracy by passing through the duct three times. It was shown that test facility also obtained data correlated with the indicated value of the measuring instrument and the dust concentration.

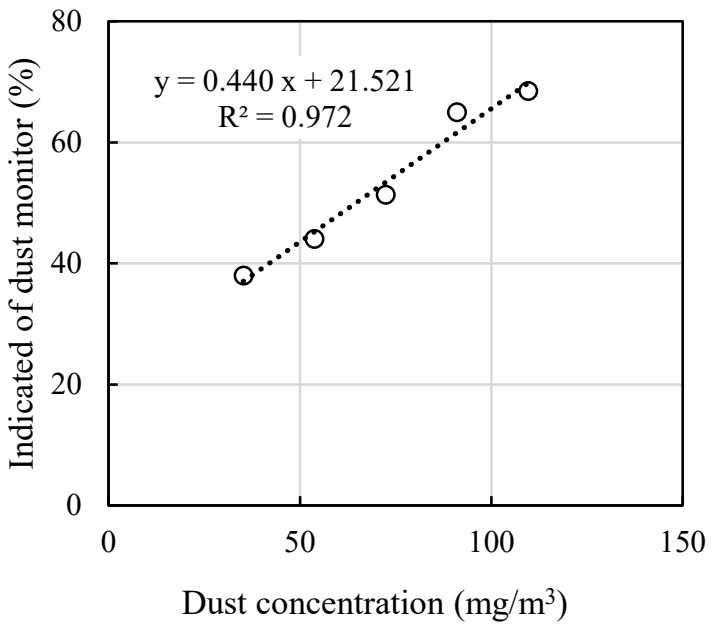

Figure 10. Relationship between the dust concentration and that indicated by the dust monitor (electro-dynamic type)

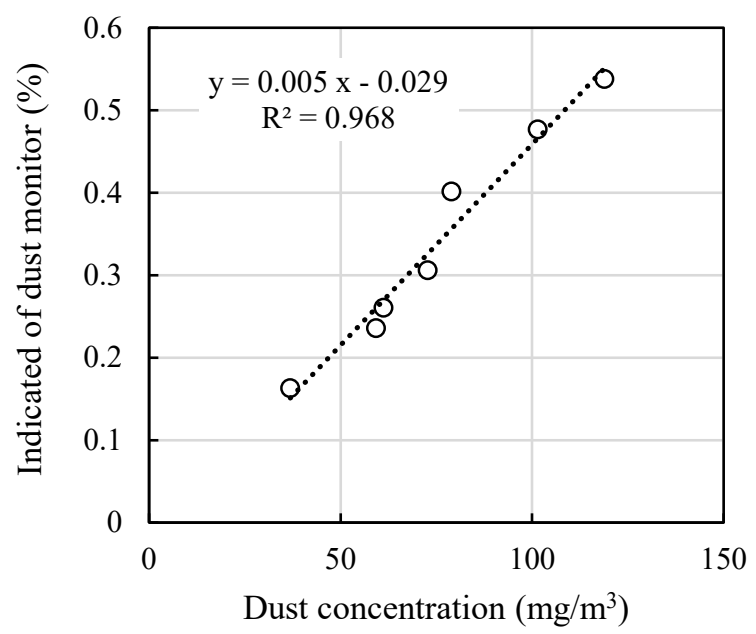

Figure 11. Relationship between the dust concentration and that indicated by the dust monitor (light transmission type).

\section{Conclusion}

A flue test facility was established to evaluate the performance of the dust monitor. By increasing the flue diameter, optimizing the rectification and dust generation, and modifying the evaluation unit, it became possible to respond to the evaluation of the main methods of dust monitoring (light scattering type, light transmission type and electrostatic detection type). Current device performance and evaluation results are reported. However, since the upper limit of the flow velocity was $10 \mathrm{~m} / \mathrm{s}$, it is necessary to work on increasing the flow velocity.

\section{Acknowledgements}

This work was supported by JSPS KAKENHI Grant Number 19K12375 and The Senshu Ikeda Bank, Ltd. Consortium Development Research Grant.

\section{References}

Castellani, B., E. Morini, M. Filipponi, A. Nicolini, M. Palombo, F. Cotana, and F. Rossi; "Comparative Analysis of Monitoring Devices for Particulate Content in Exhaust Gases," Sustainability, 6, 4287-4307 (2014)

JIS K 0302: 1989, Measuring Method for Particle-size Distribution of Dusts in Flue Gas (1989)

JIS Z 8808: 2013, Methods of Measuring Dust Concentration in Flue Gas (2013)

JIS Z 8852: 2013, Methods of Continuous Measurement for Dust Concentration in Flue Gas (2013)

JIS Z 8901: 2006, Test Powders and Test Particles (2006)

Niwa, S., T. Akutagawa, S. Sakai, M. Akiyama, N. Kogure, T. Tanaka, and H. Sega; Annual Meeting of Japan Society for Atmospheric Environment, 227 (2010)

Tamori, I.; "Introduction of JIS Z 8852-2013: Methods of Continuous Measurement for Dust Concentration in Flue Gas," Funtai gijutsu, 6, 191-193 (2014) 